change in present day psychiatry (Griffiths, 1988), certain aspects of this programme need critical but constructive monitoring. It is true that provisions of psychiatric care at primary level do help in greater understanding of mental disorders and their management, but their cost effectiveness needs to be determined (Tyrer et al, 1986). This issue becomes even more important in countries like ours, where mental health care does not enjoy priority in health planning and consequently new plans are being formulated using limited financial resources.

GRIFFTHS, R. (1988) Communtty Care: agenda for action. London: HMSO.

HANFER. H. (1987) Do we still need beds for psychiatric patients? Acta Psychiatrica Scandinavica, 75, 113-126.

JAVED, M.A. \& TAREEN, I.A.K. (1992) Community based mental health care programme. The Paktstan Journal of Clinical Psychtatry 1, 127-132.

Pakistan Psychiatric Society (1988) Psychiatry in Paktstan (Ed. S. Haroon Ahmad) Karachi: Pakistan Psychiatric Society.

TYRER, P., GILL, D. \& FARR, P. (1986) Cost of community psychiatry. British Journal of Psychiatry, 149, 795-796.

Mohammad AFzal JAVEd, and I. A. K. TAREen, King Edward Medical College/Mayo Hospital, Lahore, Pakistan

\section{People with learning disabilities: resettlement issues}

Sir: The resettlement of people with learning disabilities continues in earnest. Between 1981 and 1990, the estimated number of people resettled in England, Wales and Northern Ireland was 13,861, 436 and 232 respectively (Glover et al, 1993). The current hospital population comprises people with severe learning disabilities and superimposed behavioural/psychiatric conditions, profound and multiple physical handicaps and the frail elderly. They need 24 hour supervision and care by trained and experienced staff. Cochran et al (1977) identify preparatory steps which can minimise the distress of relocation syndrome.

Recently we resettled three elderly residents into a well-planned purpose-built, non-health authority accommodation in the community. Despite detailed and repeated exchange of information, one of the clients died a few days after discharge having sustained severe scalds in the bath. The following points emerged.

(a) Although the client was living in community, the press continued referring to him as a hospital patient. This highlights the sensitive nature of the resettlement of this vulnerable group and the need for the consultant to continue asserting a central role in planning the discharge.

(b) The lack of adequate training and expertise, coupled with ideological adherence to principles of normalisation, prevented the community staff from understanding and accepting the client needs. Important information given by the ward staff was rejected as 'negative attitudes'.

(c) The importance of written and well documented detailed exchange of information between hospital and community staff.

(d) A need for enhanced ownership of resettlement principles and policies by ward staff. In the present climate of change and unpredictability, the staff need plenty of support and encouragement.

Resettlement of a residual hospital population with learning disabilities requires a sensitive, compassionate and a well balanced approach based on sound research and experience rather than ideological concepts. The medical audit which is now an integral part of clinical practice offers an excellent opportunity to address the points highlighted.

COCHRAN et al (1977) The relocation syndrome in mentally retarded individuals. Mental Retardation. 16, 10-12.

GLOVER et al (1993) Is the money following the clients with learning disabilities? BMJ, 306, 987-990.

H. M. VERMA, Brynhyfryd Hospital, Forden, Near Welshpool, Powys SY21 8NW

\section{Use of section 4 Mental Health Act 1983}

Sir: The use of section 4 is being discouraged to such an extent that, even in situations where it is valid, demands are made for implementation of section 2. Such a situation arose recently in spite of advice to use section 4 by the senior doctor on call to the approved social worker. The patient was reported to be disturbed and verbally aggressive to his parents. The on-call GP happened to be a trainee with little experience of such patients. The social worker had no knowledge of the patient and his family. The patient had a learning disability and epilepsy and was known to the learning disability team of local social services. A decision to use section 2, rather than section 4, was made. A section 12 approved doctor was called, who had no knowledge of the patient, but he supported the section 2 for admission. Soon after admission the consultant psychiatrist, nursing staff, the patient's regular social worker and community nurse, and members of the learning disability team, discussed the circumstances of admission. It was felt that the patient had no problems of behaviour, mental illness or valid reason for admission on section 2 or 4. A social worker or community nurse with learning disability experience could have easily prevented the admission.

This case is of concern as even though the section 2 used was legally correct none of the professionals involved knew the patient or his family and yet used section 2 for admission 